\title{
EARLY PRIMARY REPAIR OF GASTROSCHISIS WITHOUT GENERAL ANAESTHESIA
}

\author{
Dhiraj Parihar' ${ }^{1}$, Nitin Goel2 ${ }^{2}$ Preeti Raikwar³ ${ }^{3}$ Arvinder Pal Singh Batra ${ }^{4}$, Jeewandeep Kaur ${ }^{5}$, Sourabh Nandi ${ }^{6}$
}

${ }^{1}$ Assistant Professor, Department of Paediatric Surgery, BPS GMC for Women, Sonepat.

${ }^{2}$ Associate Professor, Department of Paediatric Surgery, BPS GMC for Women, Sonepat.

${ }^{3}$ Associate Professor, Department of Paediatric, BPS GMC for Women, Sonepat.

${ }^{4}$ Professor \& HOD, Department of Anatomy, BPS GMC for Women, Sonepat.

${ }^{5}$ Assistant Professor, Department of Physiology (CRL), BPS GMC for Women, Sonepat.

${ }^{6}$ Senior Resident, Department of General Surgery, BPS GMC for Women, Sonepat.

\begin{abstract}
The surgical management of the abdominal wall defect has generated much discussion among paediatric surgeons. Attitudes range from primary closure whenever possible to serial closure with prosthetic material because of the hazards of tight primary closure. During the study period between Jan 2012 to June 2015, five patients of gastroschisis presented in institute (n=5). Out of five, four were inborn undergone primary repair within one hour of birth. Repair of one out born neonate was done $24 \mathrm{hr}$. after birth because of late presentation. Infants undergoing primary closure were more quickly established on full enteral feeding and discharged home significantly earlier than those either treated by primary closure under anaesthesia or by staged repair.
\end{abstract}

\section{KEYWORDS}

Gastroschisis, Primary Repair, Anaesthesia, Inborn Neonate.

HOW TO CITE THIS ARTICLE: Dhiraj Parihar, Nitin Goel, Preeti Raikwar, Arvinder Pal Singh Batra, Jeewandeep Kaur, Sourabh Nandi. "Early Primary Repair of Gastroschisis without General Anaesthesia." Journal of Evolution of Medical and Dental Sciences 2015; Vol. 4, Issue 98, December 07; Page: 16292-16294, DOI: 10.14260/jemds/2015/2403

\section{INTRODUCTION}

Babies who have gastroschisis typically are born at 34 to 38 weeks' gestational age and undergo placement of a silo or primary abdominal closure within the first few hours after birth. ${ }^{1}$ Major controversies affecting the obstetrician, neonatologist and paediatric surgeon surround the management of gastroschisis. The surgical management of the abdominal wall defect has generated much discussion among paediatric surgeons. Attitudes range from those who advocate primary closure. ${ }^{2}$ whenever possible because of the higher mortality and morbidity rates of staged repair to those who recommend serial closure with prosthetic material because of the hazards of tight primary closure. ${ }^{3}$ In this study, primary closure was attempted whenever it was considered to be safely possible. Adopting this policy based on subjective clinical judgment, infants undergoing primary closure were more quickly established on full enteral feeding and discharged home significantly earlier than those treated by staged repair.

\section{MATERIAL AND METHOD}

Its retrospective analysis of data of cases of gastroschisis treated in BPS GMC for Women Khanpur Kalan Sonepat between Jan. 2012 to June 2015.

\section{SURGICAL TECHNIQUE}

Soon after birth nasogastric and per rectal feeding tube were inserted and nasogastric aspiration and decompression of large gut was done. Intravenous antibiotic (metronidazole, amikacin and ceftriaxone) and maintenance fluids (n/3) was started. Once stable, infant was given paracetamol $(15 \mathrm{mg} / \mathrm{kg})$ rectally.

Financial or Other, Competing Interest: None.

Submission 15-11-2015, Peer Review 16-11-2015,

Acceptance 27-11-2015, Published 04-12-2015.

Corresponding Author:

Dr. Arvinder Pal Singh Batra

Professor \& HOD, Anatomy.

BPS GMC for Women, Sonepat.

E-mail: apsbatra@yahoo.com

DOI:10.14260/jemds/2015/2403
The fully conscious neonate was then placed supine, abdomen draped with sterile towel and bowel gently washed with warm saline and carefully inspected for presence of atresia or perforation. Reduction of the gut was then accomplished slowly over 5 to 10 minutes by manual returning the bowel, loop by loop, until the entire bowel was within the abdomen. Meanwhile assistant had to decompress gut by nasogastric and per rectal aspiration to assist procedure. Abdomen wall defect then closed in one layer by suturing with silk 1-0.

\section{OBSERVATIONS}

During the study period, five patients of gastroschisis presented in institute $(n=5)$. Out of five, four were inborn undergone primary repair within one hour of birth. One out born neonate was presented more than $24 \mathrm{hr}$. after birth. All patients were female with gestational age between 36 to 38 weeks and birth weight between $1.8 \mathrm{~kg}$ and $2.15 \mathrm{~kg}$.

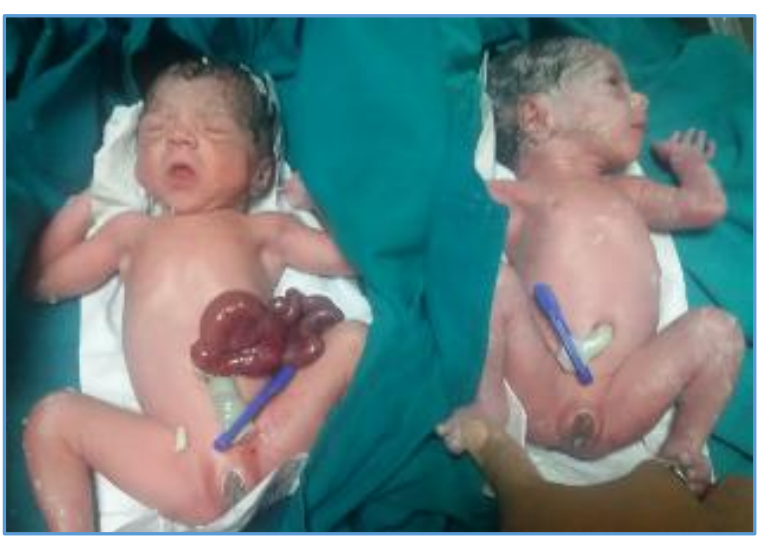

Fig. 1: Neonate of Gastroschisis with Normal Sibling

One neonate was product of twin pregnancy with normal sibling (Fig. 1). After IV access stabilization, patient was hydrated with $\mathrm{n} / 3$ saline; 10FR infant feeding tube placed nasogastric and per-rectally. Gastric and per-rectal aspiration done to decompress the gut and primary repair done in labor room (Fig. 2). 


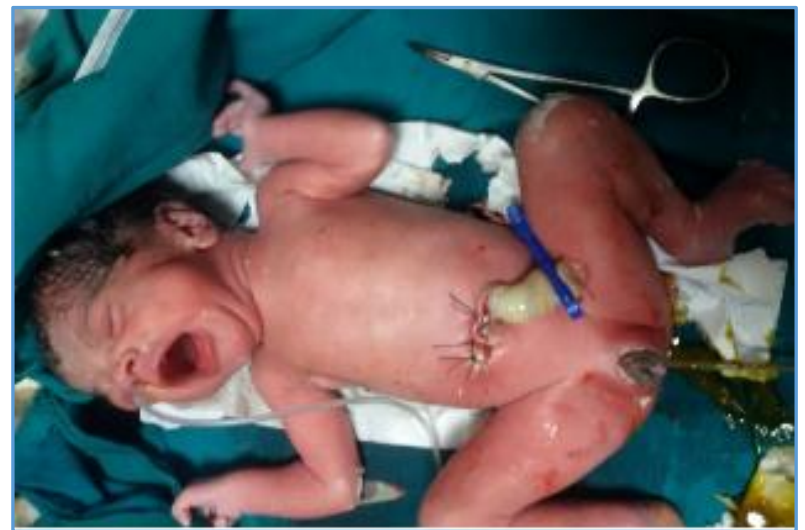

Fig. 2: Postoperative Picture of Gastroschisis

Postoperatively, patients were kept nil orally and IV antibiotic were given. Postoperative ileus was resolved within three days in three neonates and oral feeding initiated in fourth postoperative day, discharged on seventh postoperative day. In follow-up, patients were reviewed in Paediatric Surgery OPD at the age of 3 months and 6 months (Fig. 3).

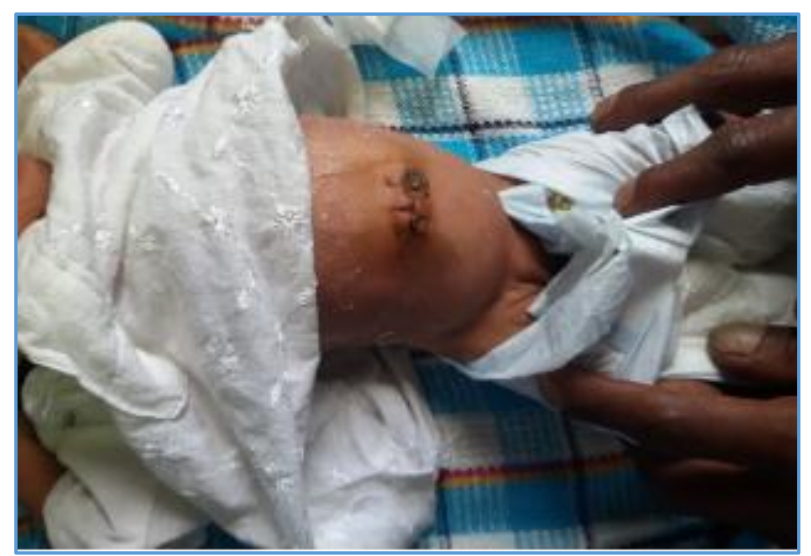

Fig. 3: Patient Followup at the Age of 1 Month

No other abnormality was found in followup ultrasound. One of inborn neonates with birth weight of $1.8 \mathrm{~kg}$ primary repair was succeeded, but $48 \mathrm{hr}$. after surgery patient developed septicemia and could not be survived. One out born neonate was presented after 48 hours of birth, had edematous bowel and thick peel formation could not be survived $72 \mathrm{hr}$. after surgery.

\section{DISCUSSION}

First successful repair of gastroschisis reported in 1943 (Watkins). ${ }^{4}$ Schuster's landmark. ${ }^{5}$ paper of 1967 reported the progressive reduction of eleven omphaloceles using a "Keel" or "Reef" of Teflon-0 mesh. His technique was modified by Allen and Wrenn. ${ }^{6}$ in 1969, who fashioned the prosthetic material into a "Silo" or "Chimney" and accomplished reduction by milking the prosthetic tube downward every 1 to 3 days.

The principles of management are to reduce the viscera safely followed by closure of the abdominal wall defect and proper nutrition support, in addition to detection and proper management of any associated anomalies or complications. ${ }^{7}$ Prenatal diagnosis and transfer of patient to a specialized center is in favor of more frequent successful primary closure, less postoperative ventilation and reduced hospital stay because of earlier surgery and early management of patient. ${ }^{8}$
Reduction of the abdominal content should be done within hours after birth, as delay in repair may cause water and heat loss from the exposed bowel, compromised gut circulation and infarction. ${ }^{1}$ Reduction of gut can be done as primary reduction or as stage reduction. Operative primary reduction with closure of the abdominal defect continued to be the standard initial surgical strategy. In 1970, pharmacologic paralysis and prolonged mechanical ventilation after aggressive attempts at primary closure were recommended. ${ }^{9}$ some authors suggest that all patients with gastroschisis may be primarily closed with paralysis and ventilator support. ${ }^{2}$

Primary repair can be done with or without general anaesthesia. Bianchi and Dickson. ${ }^{10}$ in 1998 published series of cot side reduction of 14 cases, out of them 12 were survived without anesthesia, used umbilical cord sutured to the rectus sheath to cover the defect and concluded minimal interventional management of gastroschisis is safe and applicable in our retrospective case control study and we could succeed in suturing the defect. Davies (2005). ${ }^{2}$ in his retrospective comparative study between ward reduction and repair under GA of 31 infants suggested that in ward reduction group avoided ventilation in $62 \%$ of cases and avoided GA in $81 \%$ of cases. Psychological impact on the parents of the diagnosis of Gastroschisis can be lessened if we can counsel the parents that in most cases general anaesthesia and mechanical ventilation can be avoided, also decrease in length of stay in NICU, faster time to full feeds and shorter hospital stay. However, there was a non-significant trend toward septicemia in those patients reduced on the ward without anesthesia.

Staged reduction is frequently used as a rescue strategy when reduction is deemed unsafe or physically impossible because of visceral abdominal disproportion. ${ }^{7}$ If primary closure is not possible because of insufficient size of abdominal domain, an artificial pouch or silo is constructed to contain the eviscerated abdominal content. Premade SILASTIC (Dow Corning, Midland, MI) silo with spring loaded rings (SLS) as well as various technique for silo construction are used. ${ }^{3}$ Staged closure carries the risk of loss of facial strength at the margins of the defect, the infection risk from the lack of a watertight seal and the risk of evisceration due to disrupt suture line.11

Preformed silos (Including SLS) have been used routinely without general anaesthesia and irrespective of the viscero-abdominal disproportionate. Randomized controlled trial (27 pts. in each arm) demonstrates no difference between Spring-Loaded Silo (SLS) and primary closure with respect to time on TPN, Length Of Stay (LOS), Incidence of Sepsis and Necrotizing Enterocolitis (NEC); there was a trend toward decreased days on ventilator but it was not significant.12 One of the disadvantages of SLS is the progressively increased abdominal wall defect, which may be explained by the development of lateral distractive forces being applied to the abdominal wall. ${ }^{13}$

\section{CONCLUSION}

Despite the several advantages of SLS, it has potential pitfalls including ischemic complications, dislodgment, bowel twisting and difficulties with final closure. Preformed silo is not easily available in our locality and resources are limited. Maintenance of complete asepsis for long period is not always feasible due to limited resources. Adopting this policy based on subjective clinical judgment. Infants undergoing primary closure without anaesthesia were more quickly established on full enteral feeding and discharged home significantly earlier than those either treated by primary closure under anaesthesia or by staged repair. 


\section{REFERENCES}

1. Davies MW, Kimble RM, Cartwright DW. Gastroschisis: ward reduction compared with traditional reduction under general anesthesia. Journal of Pediatric Surgery 2005;40(3):523- 527.

2. Kim R, Swartz MD, Marvin W, Harrison MD. Timothy J Campbell MD. John R Campbell, MD (1985) Selective Management of Gastroschisis Ann Surg 1986;214-18.

3. Sandler A, Lawrence J, Meehan J, Phearman L, Soper RA. "Plastic" sutureless abdominal wall closure in gastroschisis. Journal of Pediatric Surgery 2004;39(5),738-741.

4. Watkin DE, Gastroschisis. Virginia Medical Monthly, 1943;78;42.

5. Schuster SR. A new method for the staged repair of large omphaloceles. Surg Gynecol Obstet 1967;125:837.

6. Allen RG, Wrenn EL, Jr. Silon as a sac in the treatment of omphalocele and gastroschisis J Ped Surg 1969;4:3.

7. Owen A, Marven S, Johnson P, Kurinczuk J, Spark P, Draper ES, et al. Gastroschisis: a national cohort study to describe contemporary surgical strategies and outcomes. J Pediatr Surg 2010;45:1808-1816.
8. Stringer MD, Brereton RJ, Wright VM. Controversies in the management of gastroschisis: a study of 40 patients. Arch Dis Child 1991;66(1):34-36.

9. Raffensperger JG, Jona JZ. Gastroschisis. Surg Gynecol Obstet 1974;138:230-234.

10. Bianchi A, Dickson AP: Elective delayed reduction \& no anaesthesia: "Minimal intervention management" for gastroschisis. J pediatr Surg 1998;33:1338-1340.

11. Stringel G. Large gastroschisis: primary repair with GoreTex patch. J Pediatr Surg 1993;28:653-655.

12. Pastor AC, Phillips JD, Fenton SJ, Meyers RL, Lamm AW, Raval MV, et al. Routine use of a SILASTIC spring-loaded silo for infants with gastroschisis: a multicenter randomized controlled trial. Journal of Pediatric Surgery 2008;43(10),1807-1812.

13. Lobo JD, Kim AC, Davis RP, Segura BJ, Alpert H, Teitelbaum DH, et al. No free ride? The hidden costs of delayed operative management using a spring-loaded silo for gastroschisis.J Pediatr Surg 2010;45:1426-1432. 